\title{
The Role of Religious Teaching in Growth-Oriented Prevention
}

\author{
Sayyed Hossain Vaezi (Ph.D) \\ Assistant Professor, Department of Theology, Islamic Azad University Isfahan (Khorasgan) Branch, Isfahan, Iran \\ Faculty of humanities and law, Islamic Azad University, Isfahan (Khorasgan) Branch, Isfahan, Iran \\ sh.vaezi@khuisf.ac.ir \\ Akbar Kashkolli (M.A.) \\ In Criminal Law and Criminology: Islamic Azad University, Isfahan (Khorasgan) Branch \\ Faculty of humanities and law, Islamic Azad University, Isfahan (Khorasgan) Branch, Isfahan, Iran \\ Kashkolli912@yahoo.com
}

\section{Doi:10.5901/mjss.2014.v5n9p508}

\section{Abstract}

Societies have constantly faced the phenomenon of crime; and not only crime prevention measures have not led to desirable reduction of crime and deviation rate, but also criminal titles have annually been increased. However, it is observed in Islamic societies that during some lunar months such as Ramadan, crime rate is considerably descending; this indicates the power of religion to prevent and reduce crime rate. Accordingly, an aim of the present research is investigating the role of religious teachings in crime prevention trend, especially growth-oriented prevention which requires investigation of the effective role of family, science learning and ethics and explaining practical approaches to prevent delinquency. The results of this research provides profound understanding of religious teachings for the families, society, science and training centers, legislators, and other authorities and causes an appropriate approach to prevent and reduce crime rate in the society which is considered as one of the major religion-based functions for desirable control of crime.

Keywords: Religion-orientation, Crime, Growth-oriented Prevention.

\section{Introduction}

The movements which are conducted towards reinforcement and propagation of non-punitive prevention are all based on the recognition that the problem may not be solved by punitive and repressive measures and non-punitive preventive measures must be considered. However, despite various non-punitive preventive measures, failure and frustration are still the headline of speaking. The failure of all these human solutions, obviously proves the fact that absolutely relying on the wisdom and intellect, with no use of religious teachings, human beings are not able to pursue their felicity and struggle misguide and deviation (Rashad, 2003). Thus, releasing the statistics of entrance to the prisons in the country, it is observed that in some lunar months such as Ramadan and Muharram, crime rate is reduced by $35 \%$ in the society; one of its most important reasons is attention to religious issues among the community. On the other hand, the research indicates that family is one of the most important factors of growth-oriented prevention; when the family acts more actively towards religion-orientation propagation, the trend of crime and delinquency was much lower in those families than the families in them, attention to religious teachings was not a priority. The results indicate the power of religion and religionorientation on the path towards crime prevention; its precise explanation and investigation may open a window to crime rate reduction in societies.

\section{Definitions}

\subsection{Definition of Crime in terms of Criminology}

In criminology, the science which addresses the reasons for crime occurrence and the remedy for criminal actions, crime refers to all anti-social actions or the tension which cause damage to the society, with either psychological or social causes. In this area, the issue does not attract much attention that whether such actions are associated with penal code and legal definition of crime; and most dangerous states of an individual are magnified as the sign and symbol of anti- 
social behavior and a disease. Therefore, treatment of such individuals is recommended through security measures. However, due to criminological legal and social restrictions, legal definition of crime is inevitably applied and addresses the crime which is defined in penal code. In other words, legal culpable of such crime, not any other dangerous person, is investigated by criminologists, by no effort to restrict crime definition in the legal limits (Noorbaha, 2004, p.150).

\subsection{Definition of Crime Prevention in terms of Criminology}

a series of activities and measures which basically inhibit crime occurrence and activation of criminal thought and struggle the root and causes of crime emergence. Retribution is nothing other than struggle against the effect, i.e. crime; retribution is an inadequate and inefficient weapon which is unable to eliminate the root and causes of this sinister phenomenon; thus, the measures must be taken which, in advance, prohibit individuals of crime commit and also any deviation and deviated behavior (Rashad, 2003).

\section{Types of Crime Prevention}

\subsection{Penal Prevention}

Theoretical basics of penal prevention insist on official or legal methods of dealing with crime, i.e. penalty imposition and more effective measures to arrest the perpetrators, which means strengthening police and judicial system. On one hand, through criminal threats of citizens subject to criminal law, and on the other hand, by enforcement of the threat through penalizing the ones who have violated criminal prohibitions, penal prevention attempts to general and specific crime prevention. General prevention is based on the idea that penalty imposition on criminals causes the others to get scared of committing crime and consequently inhibits the crime; penalty imposition, through specific prevention, must help the offender not repeat the same crime (Reshadati, 2011).

\subsection{Non-penal prevention}

Non-penal prevention is divided to three prevention types: growth-oriented, social and situational preventions. In this type of prevention, the measures are taken which impact the individuals and fill their personality gaps. Personality gaps of individuals may either be created along with their growth or be influenced by the environment. In this method, family, environment and friends are considered in addition to the individual. Accordingly, this type of prevention can be investigated as growth-oriented prevention and society-based or social prevention (Babaei, 2011).

\subsection{Growth-oriented Prevention}

Growth-oriented prevention, as the title suggests, focuses on human growth ages. All the measures taken in this period towards the individual's growth-orientation and struggle with crime causes are called growth-oriented prevention. Growthoriented prevention, also known as Early prevention, seeks for preventing the individuals' stability in delinquency through recognition of risk factors, strengthening supportive factors and early involvement. Applying appropriate psychologicalsocial early measures, growth-oriented prevention makes an attempt to prohibit establishment and continuity of criminal behavior among individuals. Such measures, before indication at threshold of probable common differences, these measures must prevent the risk factors to which children are exposed (Reshadati, 2011).

\section{Specification and Features of Growth-Oriented Prevention}

1. Growth-oriented prevention based on Time: one of the specifications of growth-oriented prevention is that is based on time, as this type of prevention occurs during the growth period and the growth period starts from childhood and sometimes continues to 18 years old.

2. Inclusion of growth-oriented prevention to all individuals at growth ages: in growth-oriented prevention, the individuals exposed to risk or those who committed crime are not only investigated but all the individuals at growth age are vaccinated against social damage by effective preventive measures.

3. Struggle crime-causing factors before risk exposure: when crime is committed in a society, it is usually attempted to deal with the offenders and reform after crime is occurred. However, in growth-oriented prevention, the individual is made immune against probable future risks through the individual preparedness, 
and plans to tackle the crime before it occurs.

\section{Investigation of Religion and Religion-Orientation}

Expressing the features of the virtuous, Imam Ali (AS), in Sermon 193, introduces the first sign of the righteous as: "one of the signs of the virtuous is that they are observed as powerful at religiosity" (Nahjolbalagheh/Hekmat 234). Imam Sadegh (AS) also states that any of the Shiites who is not religious, is no good, as when a person is not religion-aware, the opponents will mislead them without their awareness (Ebrahimi, 2010, p 375).

\subsection{The Concept of Religion}

The word Religion means doctrine, Sharia, discipleship, obedience, capitulation, etc. (Alizadeh, 2002). The term religion is defined as "religion is the real program and actual order and blesses the human limits and is achievement of eternal bliss; all its texts and rituals are pure science and original right and includes all creatures in the universe" (Hassanzadeh Amoli, 2009, p 300). According to another definition, religion is a set instruction which is documented to divine revelation. Accordingly, "Ideology, in general, and religion, in particular, are the substantial manifestations of social life and those who assume that progress in man his knowledge cause these to be eliminated, have known neither the society structure nor the religion nature" (Motahari, 1994, p 598).

The results of the second survey of the United Nations on propensity to commit crime, 1992, in Islamic countries, non-Islamic developing countries and developed countries for the crime including assaults, murder, addiction, rape, fraud, armed robbery and other violations indicate that in all these cases, the rate of crime commit are considerably lower in Islamic countries than in other countries. As the average crime rate in Islamic countries has been 694.2 crime counts per one hundred thousand, while it is 1028.5 in developing countries and 5968.5 in developed countries; these statistics indicate the importance of religion in crime rate reduction (Serajzadeh, 2002, p 117).

\section{Religious Teachings and Growth-Oriented Prevention}

Islamic legal system comprises a huge set of religious resources and teachings, attention to any of these teachings may illuminate the path of human growth and bliss. Although Islamic education is not specific to a particular branch of subjects and includes many concepts to human excellence, a glimpse into religious teachings indicates that the holy legislator has investigated the effective factors of growth-oriented prevention through a sophisticated look along with cognition; each of the factors represents specific methods to prevent human from moving towards crime. Attention to one of the most important elements of the society, i.e., family, attention to growth ages, moral virtues, science literacy, etc. are of the items which have attracted the attention among religious teachings to growth-oriented prevention and in this regard, appropriate practical solutions are offered, including:

\subsection{Family and Its Educational role}

God Almighty says in the holly Quran: "you who believe, save yourself and your family from the fire". Family is the most important social institution as the reform infrastructure of any society is formed in families. Strengthening families cause mental and physical strength of the members. The impact of family environment as one of the external factors of delinquency has attracted specific attention of the experts. The state of family environment plays a really important role in adopting the individuals with social environment, as peace, security; compassion and love prevent many social deviations.

Although delinquency committed by children and adolescents are impacted by many factors including social, cultural, economical factors, one of the most important factors refer to the family; as the fundamentals of development and socialization of the child forms in the family and family plays a considerable role in their education (Reshadati, 2012). In this regard, the prophet of Islam (PBUH) says: "every infant is born to the clear nature of monotheism and Islam, unless the parents enter them into Judaism, Nazarene, or Zoroastrianism" (Rashad, 2004, p 372). Most children who are rejected by their parents suffer from a type of slow and shallow emotional relationship with others and lack of ethical control. Loving indulgence also causes the child to be irritable, coward and selfish. The children who are extremely waived are inconsiderate to needs and rights of the others and are not able to postpone their demands for far-fetched targets and respect the others right. The relationship between children with parents and other members of the family is really effective on personality development and social value recognition. Improper behavior and ethics, psychological 
state of parents, addiction to alcohol and narcotics undeniably affect the lack of personality development and abnormal behavior of children (Danesh, 2003).

\subsubsection{Childhood in Religious Teachings}

The research of criminologist has indicated that aggressive behavior is at its peak at the age of 2 years old. A two yearold child gradually shows dissatisfaction through aggression so that the aggressive response reduces over time. However, a minority of children continue their aggressive behavior and during their adolescence protest through such behavior and take the actions which are described as crime. Continued delinquency at older ages is also justified through the same process (Babaei, 2012)

Islam prophet (PBUH) says about the importance of childhood: "everyone who is dealing with a child must behave childish (for their education)" (Horr-e-Ameli, 2012).

Hassanzadeh Amoli stated about attention to childhood through religious texts: leave them on their own up to 7 years to strengthen themselves in three areas so that they eat well, sleep well and play well. The parents must only pay close attention that their children do not indulge, just like a gardener who plants a tree and leaves it on its own to breathe, uptake food and grow but the gardener does not irrigate it too much so that its root is not rotten or does not feed it too much so that it is not died; parents must also be careful that their children do not eat too much. Imam Sadegh (AS) states: "leave your children on their own up to seven years but be careful they do not learn bad words". If children eat well, sleep well and play well up to seven years, after that they do not indulge in eating, sleeping and playing and will have a balanced life.

Imagination control is easy before a child gets 7 years old, however, it is difficult after that time. There are some children who make much noise and nobody is able to stop them; these children become quiet as they get older, because they have vacated all the noise and naughtiness. There are also some children who sulk a lot and make peace soon, it is clear that their imagination has not become perfect. There are a few children who sulk a lot up to seven years at playground and it lasts for a long time. Unlike the children over 7, they may sulk but it is not constant. It is concluded that when the basis of a child is not prepared for taking the role, the scion which is the child does not grow and develop well and if it does not happen, first: they do not seek for improving self and second: the efforts made at older ages are often not effective; as the norms and values are institutionalized in the child (hassanzadeh Amoli, 2008, p 93).

\subsubsection{Adolescence in Religious Teachings}

In Islamic education, guidance and training of young generation is of particular importance. Adolescents own clean hearts and sensitive and emotional spirits. Considering value for their character is the best way of communicating with him. Imam Ali (AS) pays attention to acceptance of moral virtues of adolescents and the youth and says: "upon you training your adolescents, as they, ahead of the others, accept good". He also says about education of adolescents: "the best things adolescents must learn are those they will need as an adult". (Rashad, 2003, p 227). Imam Sadegh (AS) has also stated in this area: "teach your teenagers Islamic Hadith and expedite this training responsibility before misled opponents overtake you and mislead them" (Koleini, 1997, p 45). Imam Ali (AS) says to his son, Imam Mojtaba (AS), in letter 31: "the heart of an adolescent is like a prepared land that accepts any seed planted inside it" (Nahjolbalagheh, 2002).

Primary- school teachers must be much more powerful than high-school teachers, as how children are trained when at primary school, they will grow up the same. Unfortunately, in our country, a teacher with a bachelor degree teaches at high school and a teacher with an associate degree teaches at primary school; it means an about 20-year-old youth is going to make the structure of primary school and train the children. However, if the best result is intended, somebody with about 30 to 40 years of teaching experience must teach the children (Hassanzadeh Amoli, 2010, p 131).

\subsubsection{Young Ages in Religious Teachings}

The behavior method of Imam Sadegh(AS) towards the youth and his instruction for the young people and the attitude towards them is the best solution to the problems of this generation. In this regard, he says: "everyone who learns at young ages, what is learned resembles motifs on stone and everyone who learns at adulthood, the learned resembles words on water". Prophet of Islam (PBUH) stated: "God the Almighty loves the youth who spend their young ages in obedience" (Koleini, 1997, p 430). 


\subsection{Efforts to Promote Moral Virtue}

One of the issues which are emphasized in Islamic religious teachings is attention to moral virtue and to be away from moral vices that play a considerable role in growth-oriented prevention. Ethics is the science that investigates the origin of virtues, good character and the way of struggle bad character and the impact of each one on an individual and the society. In this regard, the prophet of Islam (PBUH), the greatest moral teacher, says: "surely, I was raised to complete moral virtues" and Allah says about him in holly Quran: "certainly, you have a great and worthy of ethics" (Esmaeili Yazdi, 2008, p 21).

Accordingly, ethics is defined as the science of living or the science of how to live. In fact, the way to live has two branches: how to behave and how to be. How to behave is associated with human actions including speech and how to be is associated with human nature that how and with what quality is it. (Motahari, 1994, p 610).

\subsubsection{The Importance of Moral Virtues in Religious Teachings}

According to Imam Ali (AS), ethics is the source of human happiness. He says: "even if there is no belief in God and resurrection and no fear of them, it is still necessary for the humankind to turn to right ethics, as it causes their redemption and salvation". He considers the attention to self audit as the cause for the health of individual and society. The advice of Imam Ali (AS) on self audit, pietism, asceticism, devotion, empathy and solidarity, patience, endurance, chastity and particularly avoiding secularism, avarice and egoism, are all towards development of individual and society ethics and is the role of this issue in preventing delinquency. Psychological research also indicates that crime and delinquency are accompanied with low degrees of moral reasoning and there is also a significant relationship between the type of crime committed by convicted and the stage of their ethical development (Rashad, 2003, p 317).

\subsubsection{Approaches to achieve Moral Virtue:}

Religious ceremonies: as teaching religious practice to children is not only done through the family and the experts must be utilized. Religious ceremonies are considered an effective factor to promote moral virtue. Imam Sadegh (AS) states: "any of the Shiites who is not religious has nothing good as when someone is not religion aware, the opponents may mislead them without their attention" (Alizadeh, 2003, p 33). The impact of such ceremonies not only is towards religion and religious issues but also the subjects that are sometimes in the mind of individuals, are reminded as advice that leads to a profound mental to moral virtue. To achieve this important issue, religious board, cultural centers and other religious meetings are really effective.

Mass Media: the word Media means mediator. In fact, media mediates between public citizen and official institutions. Therefore, media depicts public needs and interests. On the other hand, media adjusts the present programs and strategies according to public needs. There is extensive research on the positive and constructive role of mass media in this field. Particular importance of media is identified as the first representative of knowledge production, dissemination and promotion of science and human virtues and greatness and also as public supervisor and information server (Ranjbar and iery, 2012).

Regarding impact strategies of media, respecting some items the media are able to be leading, including attention to psychological needs of the audience through inculcation of religious beliefs and ethical values, variety creation and maintaining joyful and hopeful aspects, interpreting and analyzing news and strengthening positive thought to improve security and welfare of society, effort to investigate social deviation and stemming the reasons for deviation, emphasis on social participation, encouraging negotiation in society, re-opening feedback channels from society to decision makers, mediation and development of critical thinking, proper cultural modeling, reflecting real news, avoid alarmism, not to make news of offenders or social abnormalities, etc.

\subsection{Attention to Science Literacy and Fighting Ignorance}

One of the issues that must be attended at growth ages is attention to science literacy. This important issue has been considered. According to religion, ignorance is the opposite of wisdom. Therefore, fighting ignorance causes awakening human intellect and offering necessary knowledge to human beings and also covers both training and notice. It is enough to the importance of this issue that God has been the teacher of the prophets and God orders the prophet of Islam (PBUH) in holy Quran: "say O' Lord, increase my knowledge." 


\section{Results of Science}

Prophet of Islam (PBUH) says about the results of science: "knowledge arises to independence after it is acquired, even if it is poor; brings about generosity, even if it is apparently curmudgeon; gives splendor and grandeur to human although they come from a low-level family; brings health although they are sick; makes them near however they are far away; adorn them by modesty even if they are apparently from an unabashed family; brings about prestige and excellence although they are at a low level situation; creates dignity and greatness even if they were villainous and brings about wisdom and benefit. These are the results of science and practice for the scientist" (Ebrahimi, 2010, p 385)

\section{Investigation of the Challenges in the Process of Growth-Oriented Prevention}

\subsection{Cultural Challenges}

- The culture of crime prevention particularly religious methods of prevention has not been institutionalized and there is still extreme resistance to novel preventive methods.

- Lack of familiarity of families with training issues and attention deficit to religious teachings including religionorientation in personality development of children.

- Failure to utilize experienced teachers at primary schools, according to the importance of this level

- Deficit attention to creativity of children at primary school, teaching purely theoretical basics and consequently, lack of preparedness to accept practical professions.

- Lack of access to consultant and ethical teachers to remove religious and ethical doubts in family

- Lack of a compiled program about leisure time of the society members particularly young generation that needs activity and energy depletion.

- Identity crisis of young generation and the impact of that on crime aggravation

- Decreased commitment to religious values as an internal control factor

- Lack of sociability and proper socializing by responsible institutions such as family, school, etc.

- Failure to appropriate utilization of elite and personal preference of authorities in this field.

- Increasing deviated Internet and satellite channels that aim to overshadow religious beliefs of the public, particularly young generation.

\subsection{Legal challenges}

- The purpose of appropriate preventive measure has not been precisely explained and interpreted.

- Lack of specific judicial procedure for preventing and tackling crime and lack of attention to religious teachings when legislation

- Deficit attention to the role of religious scholars to prevent crime

- Prison inefficiency as a punitive and deterrent factor and change prison to resorts and schools for novice criminals along with lack of attention to religion-belief

- Increased criminal issues and creating a sort of confusion on the method of dealing with it.

\section{Recommendation and Approaches to Prevent Crime}

- Public and private departments coordination (official and non-official organizations) in crime prevention

- Family education on encourage their children to religious training and education

- Novel methods utilization to attract families and young people to attend religious ceremonies

- establishing free counseling centers of religious, ethical, educational and legal issues in religious places, organizations and crowded places

- taking advantage of teachers and trainers with appropriate scientific, executive, and ethical history to educate and train children at primary schools, regarding appropriate advantages

- fostering creative spirit of the students at childhood and adolescence to prevent future unemployment

- Media must reflect the information on available service, facility and opportunity for the youth.

- Effort to create value unity through strengthening religious and ethical values as the major factor to prevent 
crime.

- Serious attention to the process of socialization of society members in families, schools, universities, work places, etc and supervision and control of the process as much as possible

- Establish educational and family counseling centers in deprived and urban districts to provide necessary information in order to tackle cultural poverty of some social classes

- Set up a training program to strengthen religious institutions and attract the attention of research centers to scientific and research conferences about the role of religious teachings to prevent crime on various levels of high schools, universities, organizations, industrial centers, factories, etc.

- Set up compiled training program to strengthen cultural centers on various levels of society and formulate executive regulation for the same purpose to attract public attention and strengthen public religious beliefs.

\section{Conclusion}

Today world faces the problem of moral corruption which is of the main factors to prevent people to achieve piety. Thus, for the values and ethics to come true in the society and merge with public spirit, beliefs and lives, the living environment must be imbued with religious values. Paying attention to religious ceremonies, establishing cultural centers and utilizing the power of media could form ethical virtues at growth ages and guide them to the course of conducting so that its result is crime prevention.

Another issue is that science can be a bridge towards social prevention from committing crime, as science brings about specialty, specialty brings about technology, technology brings about employment and employment tackles poverty and unemployment. Therefore, science and ethics are of major factors to achieve an ideal society with minimum crime. Accordingly, divine religions consider special value for science and ethics and achieving this is considered as an indicator of the path of human growth and excellence.

\section{References}

Alizadeh, M. 1382, Role of Islam in preventing and reducing delinquency, first edition, Razavi university of Islamic science publication, Tehran, page 148

Babaei, M, A, 1390, Clinical criminology, first edition Mizan publication, Tehran, page 368

Danesh, T. 1381, Who is offender? What is crime?, ninth edition, Keyhan publication, Tehran, page 448.

Ebrahimi, H. 1388, Features of the righteous from the viewpoint of Imam Ali (AS), volume I, first edition, Saghalain publication, Tehran, page 637

Hassanzadeh Amoli, A. 1386, a description of heart book, volume I, fifth edition, Noboogh publication, Tehran, page 680

Hassanzadeh Amoli, A. 1388, A description of self-knowledge, volume I, Second edition, Ghaem Al-e-Mohammad pub, Tehran, page 432

Hassanzadeh Amoli, A. Science and religion, first edition, Ghaem Al-e-Mohammad pub, Tehran, page 472

Horr-e-Ameli, M. 1414(Lunar calendar), Means of Shiites to acquire issues of Sharia, Volume 19, Dar-al- ahya atarath-al-arabi, Beirut, page 653

Koleini, A. 1375, Osool-e-Kafi, volume I, translated by Kamarei, M. Osveh publication, Tehran, page 656

Motahari, M. 1374, Collected works, Volume IV, fourth edition, Sadra publication, Tehran, page 1001

Noorbahar, 1385, General criminal law, ninth edition, Tehran University publication, page 573

Rahjbar, A. Eiery, A, M. 1390, Media and crime prevention, training and Correction monthly Journal, 36: 199.

Rashad, A. 1382, Encyclopedia of Imam Ali (AS), volume V, ninth edition, Pajuheshgah Farhang va andishe eslami, Tehran, page 456

Roshandel Arbatani, T. Khoojeian, D. Ghasemi, M. 1390, Explanation of application model in mass media to prevent crime, social order and security quarterly journal, 55: 13.

Serajzaddeh H. 2002. Islam and Crime: The Moral Community of Muslims, Journal of Islamic and Arabic Studies, PP: 112-133. Available from: http:// www.lancaster.ac.uk/jais/volume/docs , [Accessed 11 May 2013]. 